\title{
Peertechz
}

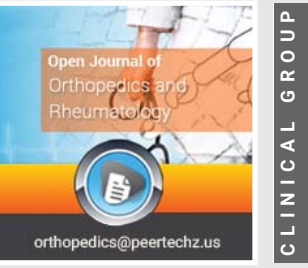

\section{Clinical evaluation of qingre jiedu quyu decoction in the treatment of systemic lupus erythematosus and its effect on NLRP3 inflammatory bodies}

Received: 14 December, 2020

Accepted: 28 December, 2020

Published: 29 December, 2020

*Corresponding author: Weidong Xu, Department of Rheumatology of Affiliated Hospital of the University of Jiangxi TCM, China, Tel: 86-15070084868; Fax: 860791-86363183; E-mail: jindadong169@163.com

Keywords: Qingre jiedu quyu decoction; Systemic lupus erythematosus; NLRP3 inflammatory corpuscles https://www.peertechz.com

\section{Check for updates}

\author{
YaXuan Fan ${ }^{1}$, Caijin $\mathrm{Cao}^{1}$, Zhiying $\mathrm{Wu}^{1}$ and Weidong $\mathrm{Xu}^{2 *}$ \\ ${ }^{1}$ The Graduate Department of Jiangxi University of Traditional Chinese Medicine, Nanchang City in \\ Jixiang Province, China \\ ${ }^{2}$ Department of Rheumatology of Affiliated Hospital of the University of Jiangxi TCM, China
}

\begin{abstract}
Objectives: To evaluate the clinical efficacy of Qingre Jiedu Quyu Decoction in the treatment of Systemic Lupus Erythematosus (SLE) and its effect on NLRP3 inflammatory bodies.

Methods: From January 2017 to December 2019, 74 patients with SLE were randomly divided into control group and observation group. The patients in the control group were given routine treatment (prednisone combined with immunosuppressive (hydroxychloroquine)). The patients in the observation group were treated with Qingre Jiedu Quyu Decoction on the basis of routine western medicine. The differences of related indexes and the changes of NLRP3 inflammatory bodies between the two groups before and after treatment were compared.

Results: The total effective rate was $94.59 \%$ in the observation group and $75.67 \%$ in the control group, there was significant difference between the two groups $(P<$ 0.05). After treatment, the SLEDAI score, NLRP3, IL-1 $\beta$ and IL-18 in peripheral blood of the two groups were significantly improved compared with those before treatment $(P$ $<0.05)$, and the observation group was superior to the control group $(P<0.05)$. There was no significant difference in adverse reactions between the two groups $(P>0.05)$.

Conclusions: Qingre Jiedu Quyu Decoction had certain clinical effect in the treatment of SLE. After treatment, the index of NLRP3, IL-1 $\beta$ and IL-18 in peripheral blood of the observation group decreased more obviously than that of the control group $(P<0.05)$.

Fund project: Funded by the National Natural Science Foundation of China in 2018-2018-40-0561; Young backbone talents training project of Traditional Chinese medicine in Jiangxi Province ;The molecular mechanism of nanorealgar in the treatment of SLE was explored from the B cell autophagy pathway which mediated by CAMP-Rap2B-PLCE-IP3R/Ca2+
\end{abstract}

\section{Text}

Systemic Lupus Erythematosus (SLE) is a highly heterogeneous autoimmune disease involving multiple systems and multiple organs, characterized by autoantibody production, complement activation and immune complex deposition [1,2].
The clinical manifestations of Systemic Lupus Erythematosus (SLE) are complex and diverse, and the etiology is not clear. At present, the routine treatment of SLE is mainly based on prednisone combined with immunosuppressive agents $[3,4]$. In recent years, with the deepening of research, the role of inflammatory corpuscles in the pathogenesis of SLE has been 
paid more and more attention. NLRP3 inflammatory corpuscles are a kind of inflammatory bodies studied in detail at present, and it plays an important role in regulating immunity by regulating IL-1 $\beta$ and IL-18 inflammatory factors [5,6]. IL-1 $\beta$ and IL-18 inflammatory factors have been proved to be closely related to SLE [7]. Now, on the basis of routine treatment, Qingre Jiedu Quyu Decoction is used to treat SLE, and to explore the effect of NLRP3,IL-1 $\beta$ and IL-18 in peripheral blood. The report is summarized as follows.

\section{Data and methods}

General data: From January 2017 to December 2019, 74 SLE patients, including 4 males and 70 females, were selected from Rheumatology Department, affiliated Hospital of Jiangxi University of traditional Chinese Medicine. The patients were randomly divided into observation group $(n=37)$ and control group $(\mathrm{n}=37)$. There were 2 males and 35 females with an average age of $(42.73 \pm 9.51)$ years and a course of disease of $(6.11 \pm 3.43)$ years in the observation group. There were 2 males and 35 females with an average age of $(41.26 \pm 11.35)$ years and a course of disease of $(6.52 \pm 3.13)$ years in the control group. There was no significant difference in the general data of the patients $(\mathrm{P}>0.05)$.

Inclusion criteria: 1 . In accordance with the diagnosis of systemic lupus erythematosus; 2 . The age was19 to 70 years old; 3. Sign informed consent for research. Exclusion criteria: 1. Those who did not conform to the diagnosis of systemic lupus erythematosus; 2. Patients with other connective tissue diseases; 3. Pregnant and lactating women; 4. Patients with severe liver, kidney and cardiovascular diseases, as well as nervous system diseases and malignant tumors; 5. A person who does not sign an informed consent.

\section{Treatment methods}

The patients in the control group were given prednisone according to $1 \mathrm{mg} /(\mathrm{Kg} \cdot \mathrm{d})$, and reduce the dosage as the symptoms decrease, as the same time treating them with hydroxychloroquine sulfate tablets (H19990234, 0.1g / tablet, Shanghai Chinese and Western Pharmaceutical Co., Ltd). One table /time, 2 times/day. The observation group was treated with Qingre Jiedu Quyu Decoction prescription(Honeysuckle $10 \mathrm{~g}$, Fructus forsythiae $10 \mathrm{~g}$,Fructus gardeniae $10 \mathrm{~g}$, Artemisia apiacea $10 \mathrm{~g}$, Scutellaria baicalensis $10 \mathrm{~g}$, Rhizoma anemarrhenae 10g, Moutan bark 10g,Radix ophiopogonis $10 \mathrm{~g}$, Radix Paeoniae root $10 \mathrm{~g}$, Glycyrrhiza $6 \mathrm{~g}$ ) on the basis treatment of the control group, 1 dose a day, 2 times in the morning and evening.Both the control group and observation group were treated 12 weeks.

\section{Observation indicators}

The peripheral venous blood of the patients in the group was taken at $5 \mathrm{~mL}$. After centrifugation, the upper plasma was taken and frozen in the refrigerator at $-20^{\circ}$ for examination. The expression of NLRP3 inflammatory corpuscles (purchased from Wuhan Kangshengda Medical Company), IL-1 $\beta$ and IL18 (Wuhan Kangshengda Medical Company) was detected by enzyme-linked immunosorbent assay (Elisa). The specific operation steps were strictly carried out, and the changes of NLRP3,IL-1 $\beta$ and IL-18 were recorded.
The changes of Erythrocyte Sedimentation Rate (ESR) tested by Automatic ESR accumulator tester, C-Reactive Protein (CRP) tested by ELASE and adverse reactions of Systemic Lupus Erythematosus Index (SLEDAI) were observed before and after treatment.

\section{The curative effect evaluation}

Referring to the diagnostic curative effect standard issued by the State Administration of traditional Chinese Medicine [8], which is excellent, effective and ineffective to evaluate the curative effect. Excellent: after 12 weeks of treatment, the main clinical symptoms of the patients basically disappeared, and the results of laboratory index examination were close to normal; effective: after 12 weeks of treatment, the main clinical symptoms of the patients improved and the laboratory indexes improved; ineffective: after 12 weeks of treatment, the main clinical symptoms of the patients were not improved or aggravated, and the laboratory examination indexes were aggravated. The total effective rate, that was the total effective rate $=$ (the number of effective cases + the number of effective cases) / the total number of cases $\times 100 \%$.

\section{Statistical methods}

It were analyzed by SPSS 24.0 software. The measurement data were expressed by $\mathrm{x} \pm \mathrm{s}$, the independent sample $\mathrm{t}$ test was used between the two groups, and the matched sample t test was used in the comparison between the two groups, and the difference between the two groups was statistically significant $(\mathrm{P}<0.05)$. The counting data were statistically significant by $\chi^{2}$ test $(\mathrm{P}<0.05)$.

\section{Results}

The effective rate was $94.59 \%$ in the observation group and $75.67 \%$ in the control group. There was significant difference between the two groups $(\mathrm{P}<0.05)$ Table 1.

The clinical indexes of ESR, CRP, IL-1 $\beta$, IL-18 and NLRP3 in the two groups were improved after treatment, and the difference was statistically significant $(\mathrm{P}<0.05)$, and the observation group was superior to the control group $(\mathrm{P}<0.05)$, Tables 2,3.

The scores of systemic lupus erythematosus index (SLEDAI) in the two groups were improved after treatment, the difference was statistically significant $(\mathrm{P}<0.05)$, and the observation group was superior to the control group, Table 4 .

The adverse reaction rates between the two groups, there was no significant difference in adverse reactions between the two groups $(\mathrm{P}>0.05)$, Table 5 .

Table 1: Comparison of clinical efficacy between the two groups.

\begin{tabular}{|c|c|c|c|c|c|}
\hline Group & $\mathbf{n}$ & Excellence & Effective & Invalid & Total validity \\
\hline Observation group & 37 & 20 & 15 & 2 & 35 \\
\hline Control group & 37 & 10 & 18 & 9 & 28 \\
\hline$X^{2}$ & & & & & 5.232 \\
\hline P & & & & & 0.022 \\
\hline
\end{tabular}

Citation: Fan Y, Cao C, Wu Z, Xu W (2020) Clinical evaluation of qingre jiedu quyu decoction in the treatment of systemic lupus erythematosus and its effect on NLRP3 inflammatory bodies. Open J Orthop Rheumatol 5(1): 069-072. DOI: https://dx.doi.org/10.17352/ojor.000030 
Table 2: Comparison of ESR, CRP, IL-1 $\beta$ between the two groups.

\begin{tabular}{|c|c|c|c|c|c|c|}
\hline \multirow[t]{2}{*}{ Group } & \multicolumn{2}{|c|}{$\operatorname{ESR}(\mathrm{mm} / \mathrm{h})$} & \multicolumn{2}{|c|}{$\mathrm{CRP}(\mathrm{mm} / \mathrm{h})$} & \multicolumn{2}{|c|}{$\mathrm{IL}-1 \beta$} \\
\hline & Before treatment & After treatment & Before treatment & After treatment & Before treatment & After treatment \\
\hline Observation group & $41.57 \pm 10.208$ & $9.08 \pm 2.543$ & $43.70 \pm 12.19$ & $9.73 \pm 2.653$ & $18.13 \pm 1.34$ & $9.55 \pm 5.17$ \\
\hline Control group & $39.86 \pm 10.034$ & $15.62 \pm 4.832$ & $40.11 \pm 10.113$ & $16.97 \pm 4.764$ & $\begin{array}{c}16.14 \pm \\
5.74\end{array}$ & $13.71 \pm 2.64$ \\
\hline $\mathrm{t}$ & 0.724 & 7.286 & 1.380 & 8.081 & 1.565 & 8.522 \\
\hline$P$ & 0.472 & 0.000 & 0.172 & 0.000 & 0.122 & 0.000 \\
\hline
\end{tabular}

Table 3: Comparison of IL-18 and NLRP3 between the two groups.

\begin{tabular}{|c|c|c|c|c|}
\hline & \multicolumn{2}{|c|}{ IL-18 } & \multicolumn{2}{c|}{ NLP3 } \\
\hline & $\begin{array}{c}\text { Before } \\
\text { treatment }\end{array}$ & $\begin{array}{c}\text { After } \\
\text { treatment }\end{array}$ & $\begin{array}{c}\text { Before } \\
\text { treatment }\end{array}$ & $\begin{array}{c}\text { After } \\
\text { treatment }\end{array}$ \\
\hline $\begin{array}{c}\text { Observation } \\
\text { group }\end{array}$ & $18.13 \pm 5.17$ & $9.55 \pm 1.34$ & $13.45 \pm 3.41$ & $9.66 \pm 0.729$ \\
\hline Control group & $16.14 \pm 5.74$ & $13.71 \pm 2.64$ & $14.64 \pm 3.51$ & $12.10 \pm 1.70$ \\
\hline $\mathrm{t}$ & 1.565 & 8.522 & 1.477 & 8.022 \\
\hline $\mathrm{P}$ & 0.122 & 0.000 & 0.144 & 0.000 \\
\hline
\end{tabular}

Table 4: Comparison of SLEDAI score between the two groups.

\begin{tabular}{|c|c|c|}
\hline Group & \multicolumn{2}{|c|}{ Sledai } \\
\hline & Before treatment & After treatment \\
\hline Observation group & $14.32 \pm 2.897$ & $3.27 \pm 1.283$ \\
\hline Control group & $13.84 \pm 3.158$ & $6.51 \pm 1.82$ \\
\hline $\mathrm{t}$ & 0.691 & 8.859 \\
\hline $\mathrm{P}$ & 0.492 & 0.000 \\
\hline
\end{tabular}

Table 5: Comparison of adverse reaction rates between the two groups.

\begin{tabular}{|c|c|c|c|c|c|c|}
\hline Group n & $\mathbf{n}$ & $\begin{array}{l}\text { Gastrointes- } \\
\text { tinal } \\
\text { discomfort }\end{array}$ & hyperglycemia & $\begin{array}{c}\text { Elevation } \\
\text { of blood } \\
\text { pressure }\end{array}$ & osteoporosis & $\begin{array}{c}\text { Total } \\
\text { incidence } \\
\text { rate }\end{array}$ \\
\hline $\begin{array}{l}\text { Observation } \\
\text { group }\end{array}$ & 37 & 3 & 1 & 3 & 3 & 10 \\
\hline $\begin{array}{l}\text { Control } \\
\text { group }\end{array}$ & 37 & 5 & 2 & 5 & 2 & 14 \\
\hline$x^{2}$ & & & & & & 0.987 \\
\hline $\mathrm{P}$ & & & & & & 0.321 \\
\hline
\end{tabular}

\section{Discussion}

SLE is an autoimmune disease, which can involve all systems of the whole body, and the clinical manifestations are complex and diverse. SLE is prone to occur in women of childbearing age and seriously affects people's quality of life [9]. At present, there is still a lack of rational drugs in the treatment of SLE, It is mainly hormone combined with immunosuppression agents,but hormone and immunosuppression side effects are greater [10]. Clinical use of western medicine, especially glucocorticoid, can cause a series of adverse reactions, such as gastric ulcer, immunosuppression and infection, osteoporosis and obesity. And immunosuppressant such as cyclophosphamide can lead to bone marrow suppression, digestive tract reaction, opportunistic infection changes and other .This study showed that Qingre Jiedu Quyu Decoction could improve clinical symptoms, reduce SLEDAI score, ESR,CRP and so on. In addition, we observed that NLRP3,IL-1 $\beta$ and IL-18 in peripheral blood of patients after treatment were lower than those before treatment, which suggested that NLRP3 inflammatory bodies, IL-1 $\beta$, IL-18 were closely related to the progression of SLE.

NLRP3 inflammatory corpuscles is one of the inflammatory corpuscles, which plays an important role in the human immune system and help the human body resist infection, but the over-activated NLRP3 inflammatory bodies is involved in the pathogenesis of SLE. NLRP3 inflammation bodies can activate aspartate specific cysteinase (caspase)-1, and then regulates the maturation and releases of IL-1 $\beta$ and IL-18. Studies have shown that the role of inflammatory factors such as IL-1 $\beta$ and IL-18 in the treatment of SLE was confirmed at the animal level for a long time [11]. Li, et al. [12] confirmed that NLRP3 inflammatory bodies were significantly upregulated in the kidneys of MRL / lpr lupus mice, and block NLRP3 inflammatory bodies could weaken the severity of MRL / lpr lupus mice. Over expression of NLRP3 inflammatory bodies aggravates organ damage in lupus mice, which indicates that NLRP3 inflammatory bodies play an important role in the pathogenesis of systemic lupus erythematosus.

SLE has not been recorded in traditional Chinese medicine, but there are similar clinical symptoms between "red acne "," face sore "," yin and yang poison" and "arthralgia syndrome" and SLE. SLE is due to the lack of innate endowment, complex feeling six harlot, toxic evil,conclusion the disease pathogenesis is essential empty and out solid as the core pathogenesis. The pathogenesis of this disease belongs to the deficiency of the standard, the deficiency of the viscera as the basis, heat toxin, blood stasis as the standard, in which the deficiency of the viscera is mainly liver, spleen and kidney, which is consistent with the views of most doctors. The SLE is the congenital endowment insufficiency, the seven feelings internal injury or the fatigue excessive, under the external evil attack, the sunlight exposure, the medicine injury and so on condition, the evil depression turns the fire, the yin and yang imbalance, but causes the viscera qi machine disorder, the qi and blood movement disorder, thus affects the body entire body each tissue organ [13]. Traditional Chinese medicine treatment of SLE can not only improve the clinical efficacy, promote the stability of the disease, but also improve the clinical symptoms, improve the quality of life, at the same time, reduce the amount of hormones, reduce the adverse reactions and complications of hormones and immunosuppressants [14]. Honeysuckle and Fructus forsythiae are as the monarch medicine, clearing heat and detoxifying ;Fructus gardeniae,Artemisia apiacea ,Scutellaria baicalensis, Rhizoma anemarrhenae are as the 
minister medicine, complementing each other, playing the effect of clearing heat and detoxifying dampness, with Moutan bark,Radix ophiopogonis , Radix Paeoniae root to remove blood stasis and nourish yin,Glycyrrhiza to reconcile the drugs. The whole prescription plays the effect of clearing heat and detoxifying, removing dampness and removing blood stasis.

In summary, Qingre Jiedu Quyu Decoction had certain curative effect in the treatment of systemic lupus erythematosus. However, the number of cases included in this study was relatively small, so large samples and longterm clinical efficacy observation were still needed. This study showed that the levels of NLRP3,IL-1 $\beta$ and IL-18 in peripheral blood of the observation group were more significantly lower than those of the control group after treatment $(\mathrm{P}<0.05)$. This suggested that the mechanism of Qingre Jiedu Quyu Decoction in the treatment of SLE might be related to NLRP3 inflammatory bodies and their regulated inflammatory factors IL-1 $\beta$ and IL-18, which needed to be further explored.

\section{Acknowledgments}

A total of 4 members of this research team, all agreed to submit the paper to the journal without any conflict of interest between the authors of the article, and it can be determined that the manuscript has not been currently submitted in any other journal.

\section{References}

1. Fava A, Petri M (2019) Systemic lupus erythematosus: Diagnosis and clinical management. J Autoimmun 96: 1-13. Link: https://bit.ly/3aKo4D6

2. Olesińska M, Saletra A (2018) Quality of life in systemic lupus erythematosus and its measurement. Reumatologia 56: 45-54. Link: https://bit.ly/38F1qt1

3. Lopez R, Davidson JE, Beeby MD, Egger PJ, Isenberg DA (2012) Lupus disease activity and the risk of subsequent organ damage and mortality in a large lupus cohort. Rheumatology 51: 491-498. Link: https://bit.ly/3aV7gsW
4. Carter EE, Barr SG, Clarke AE (2016) The global burden of SLE:prevalence, health disparities and socioeconomic impact. Nat Rev Rheumatol 12: 605-620. Link: https://bit.ly/3nVClka

5. Tschopp J, Schroder K (2010) NLRP3 inflammasome activation:The convergence of multiple signalling pathways on ROS production?. Nat Rev Immunol 10: 210-215. Link: https://bit.ly/2L4FnDV

6. Reeves WH (2014) Systemic lupus erythematosus:death by fire and ICE? Arthritis Rheum 66: 6-9. Link: https://bit.ly/3nUlkH9

7. Siling C, Yi T, Ruilin C (2017) Expression and significance of serum IL-1 and IL-18 in patients with systemic lupus erythematosus. Guangdong Medica Science 38: 2473-2475

8. National Administration of Traditional Chinese Medicine. Standards for Diagnosis of TCM Diseases. Nanjing: Nanjing University Press, 1994:186.

9. Lopez R, Davidson JE, Beeby MD, Egger PJ, Isenberg DA (2012) Lupus disease activity and the risk of subsequent organ damage and mortality in a large lupus cohort. Rheumatology 51: 491-498. Link: https://bit.ly/3aV7gsW

10. Carter EE, Barr SG, Clarke AE (2016) The global burden of SLE: prevalence, health disparities and socioeconomic impact. Nat Rev Rheumatol 12: 605620. Link: https://go.nature.com/2WPrlc5

11. Elena V, Molly D, Heidy Z, Lubov G, Jian-Ping L, et al. (2006) IL-1 beta-deficient mice are resistant to induction of experimental SLE. European Cytokine Network 17: 109-116. Link: https://bit.ly/3aTxoVr

12. Xiuzhen L, Mengjun W, Hong H, Congjuan L, Zewei L, et al. (2018) Sophocarpine attenuates murine lupus nephritis via inhibiting NLRP3 inflammasome and NF-kB activation. Immunologic Research 66: 521-527. Link: https://bit.ly/3hotWTZ

13. Dan-dan Z, Yong-Sheng F, Cheng-Ping W (2016) Take systemic lupus erythematosus as an example to analyze the thought of the overall treatment and the stage treatment of chronic stubborn diseases. Chinese Journal of Traditional Chinese Medicine 31: 4623-4625. Link: https://bit.ly/3plYCrE

14. Weiwei C, Li S, Xiao S, Jia X (2019) Thinking and Method of Treating Systemic Lupus Erythematosus with TCM in Contemporary Medical Expert. Chinese Journal of Traditional Chinese Medicine 37: 922-924.

Discover a bigger Impact and Visibility of your article publication with

Peertechz Publications

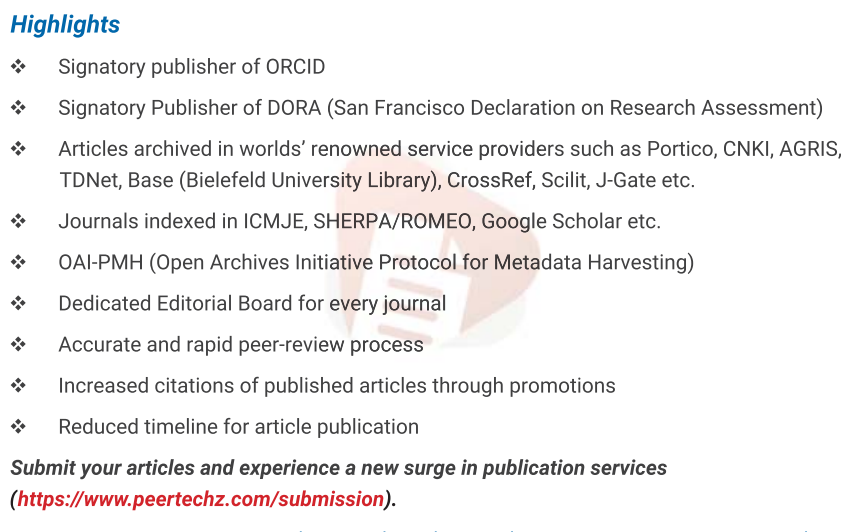

Peertechz journals wishes everlasting success in your every endeavours.

Copyright: @ 2020 Fan Y, Cao C, et al. This is an open-access article distributed under the terms of the Creative Commons Attribution License, which permits unrestricted use, distribution, and reproduction in any medium, provided the original author and source are credited.

Citation: Fan Y, Cao C, Wu Z, Xu W (2020) Clinical evaluation of qingre jiedu quyu decoction in the treatment of systemic lupus erythematosus and its effect on NLRP3 inflammatory bodies. Open J Orthop Rheumatol 5(1): 069-072. DOI: https://dx.doi.org/10.17352/ojor.000030 